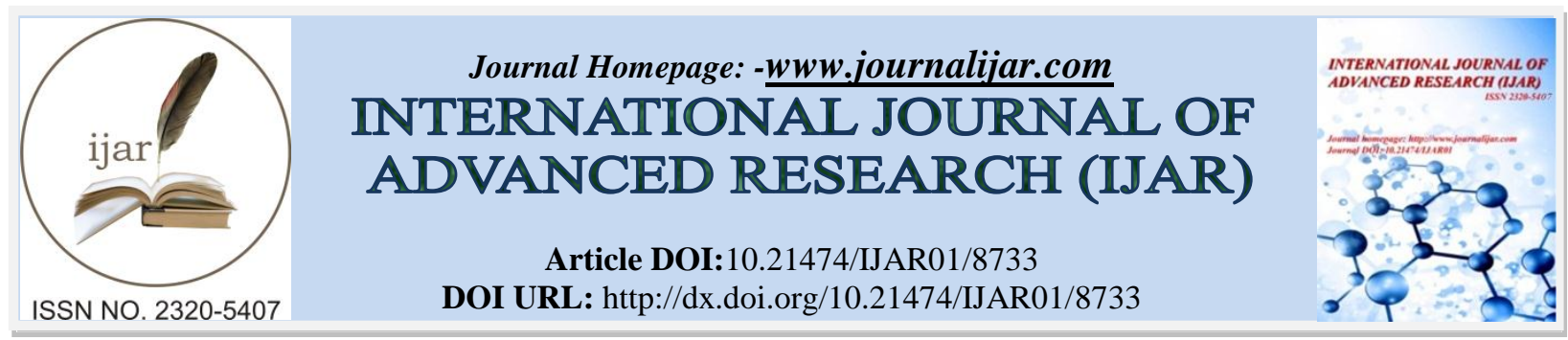

RESEARCH ARTICLE

\title{
EFFECT OF NEEM AND LUBRICATING OILS (85W90) AS QUENCHANTS ON THE MECHANICAL PROPERTIES OF GAS METAL ARC WELDED DUPLEX STAINLESS STEEL.
}

1. Federal University Wukari, Taraba state, Nigeria.

Ibrahim, T. $K^{1}$., Thaddaeus, $\mathbf{J}^{1}$., Luka, B. $S^{1}$ and Leva, I. $\mathbf{U}^{2}$.

2. Department of Mechanical Engineering, University of Agriculture Makurdi, Benue State.

\section{Manuscript Info}

(..........................

Manuscript History

Received: 18 January 2019

Final Accepted: 20 February 2019

Published: March 2019

Key words:-

Duplex Stainless Steel, Hardness

Number, heat treatment, Impact Energy, and Tensile Strength

\section{Abstract}

The effect of using neem oil, gear Oil (85W90) as quenchants and stress relief heat treatment on mechanical properties of gas metal arc welded duplex stainless steel were studied and compared. The samples after welded were given post weld heat treatments which are stressrelief and quenching in lubricating and neem oil. The results of the studies show that quenching in neem and lubricating oils ( $85 \mathrm{w} 90)$ improved some mechanical properties of the alloy after welding (i.e toughness and ductility). The research also shows that the stress relief heat treatment gives better strength compared to those that were quenched in lubricating oil (85W90) and neem oil but the reverse is the case in terms of toughness and ductility.

Copy Right, IJAR, 2019,. All rights reserved.

\section{Introduction:-}

Duplex stainless steels present an attractive combination of mechanical and corrosion resistance and are widely used in the marine and petrochemical industries [Badji et al, 2008]. Duplex stainless steels are two phase microstructure, containing both austenite and ferrite, as a result of this specific microstructure, it combines to certain extent the advantage of the two sides. Duplex stainless steels are ferromagnetic, a property that can easily differentiate them from common austenitic grades of stainless steels. Generally the ratio of ferrite to austenite in duplex stainless steels depends mainly on the chemical composition. The presence of ferrite with austenite provides better intergranular corrosion (IGC) resistance, other advantages offered by these alloys over convection 300 series stainless steels are strength, chloride stress-corrosion cracking resistance, and pitting corrosion resistance [Gunn, 1997; Ibrahim et al, 2016].

Duplex stainless steels are increasingly used as structural materials in building and architecture because of their exceptional mechanical properties. Their room temperature yield strength in the solution annealed condition is more than twice that of standard austenitic stainless steels not alloyed with nitrogen. Over the last few years, they have started playing an increasingly important role in the construction of bridges, wherever specific environmental conditions combine with the need for high load-bearing capability. Duplex stainless steels are mostly selected because of their combination of high strength and corrosion resistance. Their full potential is used in locations where the material comes into contact with salt water, or where high concentrations of chlorides are present in the ambient air or where de-icing salts are of a concern [Ibrahim et al, 2013].

With all their afore-mentioned favorable properties, they still fail mostly at the weld points which can be as a result of the welding process, process variables used and the welding environmental contamination [Bhaduri et al 2003]. 
Hence, this research work is to compare the effect heat treatments on the mechanical properties of welded duplex stainless steels. The mechanical properties that were investigated are; tensile strength, impact strength and hardness, as we already know that the durability of a welded structure directly depends on the resulting mechanical properties after welding [Ibrahim et al, 2013].

\section{Material and Method:-}

\section{Materials.}

Duplex stainless steel was the main material used for this research work which was sourced locally at Jos building materials market, while its chemical composition (see table 2) was determined at National Metallurgical Center Jos Nigeria using the XFR test. Other materials that were used are: lubricating oil $85 \mathrm{~W} 90$, neem oil, Nertalic 50 wire electrode, and etchant.

\section{Methodology}

\section{Pre-Welding Sample Preparation.}

The duplex stainless steel rod was cut into equal pieces (samples) of length $100.2 \mathrm{~mm}$; they were further cut into two equal parts. All the samples for welding were prepared as shown in fig.1 below
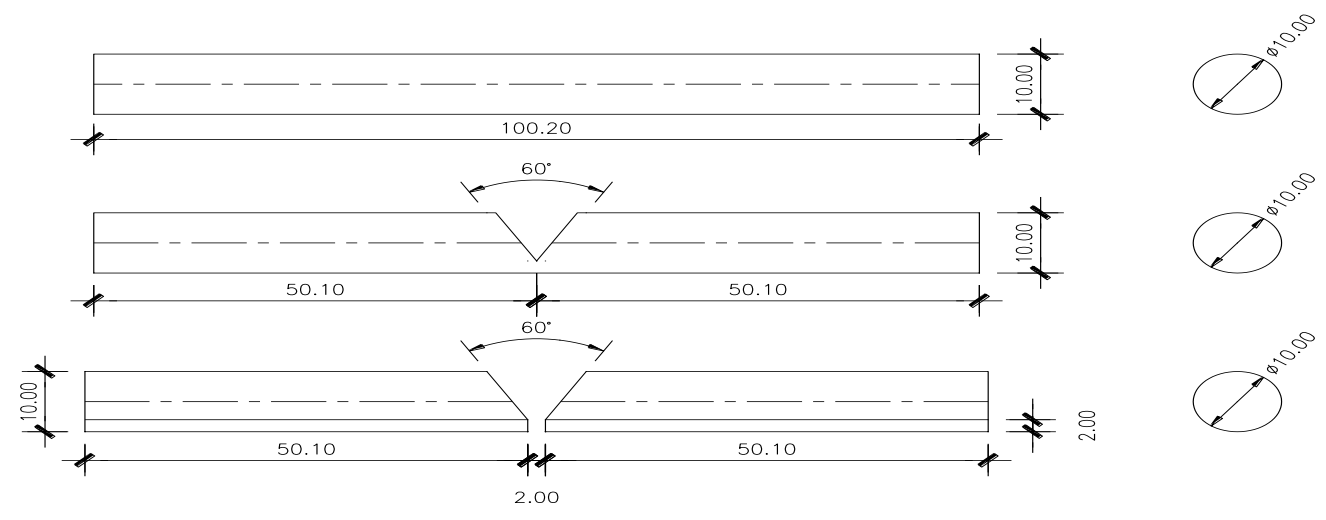

Fig 1:-joint preparation for V-groove welding [Gunn, 1997; Ibrahim et al, 2016].

Samples were cleaned of dirt and oil and a grinding machine was used to grind the surfaces of samples prior to welding in order to have smooth and uniform surfaces according to Dauda [2008].

\section{Welding Procedure}

The shield metal arc welding process was used to weld over one hundred samples respectively. They were laid on an angle bar with their beveled edges parallel and facing each other, leaving a root face and root opening of $2 \mathrm{~mm}$ with an included angle of $60^{\circ}$ then an arc was struck. The first bead was laid down at the root of the joint to ensure equal fusion in both rods, before the second bead was laid the first bead was allow to cool down to about $150^{\circ} \mathrm{C}$. Any slag noticed was removed before an additional bead was laid. The welding parameters are shown in table 3.1. The number of passes used was two on each of the sample; the second pass was to fill the grove and to produce a crown [Ibrahim et al, 2016]

Both welded samples were cleaned of dirt and oil. The grinding machine was used to grind the surfaces of samples after welding in order to have smooth and uniform surfaces.

\section{Post-Welding Thermal Treatment.}

Two post thermal heat treatments were adopted viz:

1. Stress relieve annealing

2. Hardening by quenching.

\section{Stress-Relieve Annealing}

This treatment was done by heating the samples from ambient temperature up to $600^{\circ} \mathrm{C}$, and then soaked at this temperature for 30 minutes. After which they were removed from the furnace and air cooled back to ambient temperature. [Ibrahim et al, 2013] 


\section{Quenching and Tempering.}

Samples, that had been previously stress relieved were again heated to the temperature of $900^{\circ} \mathrm{C}$ and remained at this temperature for 30 minutes, they were then quickly removed and plunged into a can of either engine oil or Neem oil at room temperature. The quenched samples were tempered slowly by reheating them to $300^{\circ} \mathrm{C}$ and allowed to soak for 30 minutes, after which they were removed from the furnace and allowed to cool to room temperature in air.

\section{Mechanical Test Procedure Tensile Strength Test}

Tensile strength indicates the ability of a composite material to withstand forces that pull it apart as well as the capability of the material to stretch prior to failure. Tensile tests were carried out using a Hounsfield Tensiometer, with maximum load of $250 \mathrm{KN}$. The standard samples were mounted by their ends into the holding grips of the testing apparatus.

The machine is designed to elongate the sample at a constant rate, and to measure the instantaneous applied load and the resulting elongations simultaneously using an extensometer.

\section{Charpy Impact Test}

Charpy Impact tests were conducted in accordance with ASTM A370 "Standard Methods and Definitions for Mechanical Testing of Steel Products", and ASTM E23, "Standard Method for Notched Bar Impact Testing of Metallic Materials". The Charpy V-notch samples, used in this evaluation, were machined according to the specification in ASTM E23 and Tanimu Ibrahim et al as shown in figure below.

\section{Hardness Test.}

The hardness values of the samples were determined according to the provisions in ASTM E18-79 using the Rockwell hardness tester with a $1.56 \mathrm{~mm}$ steel ball indenter, minor load of $10 \mathrm{Kg}$, and major load of $150 \mathrm{Kg}$ and harness value of 56.4HRC as a standard block. Before the test, the mating surface of the indenter, plunger rod and the test samples were thoroughly cleaned by removing the dirt, scratches and oil.

\section{Microstructural Analysis \\ Surface Preparation}

The surfaces of samples for metallographic examination were ground and polished. The grinding process was performed using silicon carbide papers of varying grits starting with the coarsest grit size of 120 . Subsequently grit size of 240, 320, 400 and 600 were used. The grinding was done wet with the aid of a lubricant. The lubricant were applied intermittently to prevent overheating of the sample and to provide a rinsing action to flush away the particles being removed from the surface.

Polishing was carried out using a silicon abrasive in form of a very fine powder (1000 grit). The powder was applied to a wet polishing wheel rotating in the clockwise direction. The samples were polished by rotating them in the direction opposite to the direction of rotation of the wheel. This resulted into a shiny, scratch free surface ready for etching and microscopy [ Ibrahim et al, 2013].

\section{Etching}

Etching was done to expose and make visible the grains of the samples structural characteristics of the sample under the different conditions of heat treatment, as received and as welded. The etching was done using $10 \mathrm{cc}$ of $\mathrm{HCl}, 3 \mathrm{cc}$ $\mathrm{HNO}_{3}$ and $100 \mathrm{cc}$ distilled water.

\section{Scanning Electron Microscope Analysis}

Samples after preparation were attached to multi-stub sample holder with the use of double sided conductive aluminum tape, after which, they were mounted onto the sample chamber, while the column was put at vacuum. After reaching the vacuum target, the electron gun was switched on which passed an accelerating voltage of $20 \mathrm{kV}$ and probe current of $227 \mathrm{pA}$ through the samples at a working distance of $7.0 \mathrm{~mm}$ and $6.0 \mathrm{~mm}$.

Micrographs of the Samples were taken at two different positions viz; the fusion Zone (FZ) and the heat affected Zone (HAZ). The scanning electron microscope (SEM) EVO MA-10 manufactured by Carl, was used for the analysis at Sheda Science and Technology Complex, Abuja Nigeria. 


\section{Samples Labeling}

The samples after preparation were labeled as follows before testing them; this is also referred to the the discussion of results.

Table 2:-Samples Labeling

\begin{tabular}{|l|l|}
\hline Sample A & Sample that was welded with GMAW method without heat treatment \\
\hline Sample A1 & Sample that was welded with GMAW and Quenched in NEEM oil (heat treated) \\
\hline Sample A2 & Sample was welded with GMAW and Quenched in Engine oil(heat treated) \\
\hline Sample A3 & Sample that was welded with GMAW and undergo Stress Relief heat treatment \\
\hline Sample C & As received \\
\hline
\end{tabular}

\section{Results and Discussion:-}

\section{Chemical Composition of Research Material}

$\mathrm{X}$ ray florescence test was used to determine the actual chemical composition of the research material. Table below shows the results of XRF test carried out on the material as received from the manufacturing company.

Table 3:-Research Material Chemical Composition

\begin{tabular}{|l|l|l|l|l|l|l|l|l|l|}
\hline Element & $\mathrm{C}$ & $\mathrm{Si}$ & $\mathrm{Mn}$ & $\mathrm{P}$ & $\mathrm{S}$ & $\mathrm{Cr}$ & $\mathrm{Ni}$ & $\mathrm{Mo}$ & $\mathrm{Al}$ \\
\hline \%by wt & $\begin{array}{l}0.02- \\
0.05\end{array}$ & 0.238 & 1.57 & 0.036 & 0.032 & $>9.96$ & $>6.60$ & 0.342 & 0.011 \\
\hline Element & $\mathrm{V}$ & $\mathrm{W}$ & $\mathrm{Pb}$ & $\mathrm{B}$ & $\mathrm{Sn}$ & $\mathrm{Zn}$ & $\mathrm{As}$ & $\mathrm{Bi}$ & $\mathrm{Ca}$ \\
\hline \%by wt & 0.106 & 0.036 & $>0.003$ & $<0.0005$ & 0.012 & 0.029 & $<0.001$ & 0.009 & 0.0015 \\
\hline Element & $\mathrm{Cu}$ & $\mathrm{Co}$ & $\mathrm{Ti}$ & $\mathrm{Nb}$ & $\mathrm{Ce}$ & $\mathrm{Zr}$ & $\mathrm{La}$ & $\mathrm{Fe}$ & \\
\hline \%by wt & 0.302 & 0.132 & 0.011 & 0.046 & 0.031 & 0.0015 & 0.0043 & 69.6 & \\
\hline
\end{tabular}

The results of the research material chemical composition as shown on table 4.1, prove that the material is actually a duplex stainless steel. This is due to the presence of high percentage composition of iron ( $\mathrm{Fe})$ as the base material, chromium (Cr) and manganese (Mn) as major alloying elements, low percentage of Carbon (C) and other trace elements. This is in close agreement with the chemical composition of Duplex stainless steel grade (www.azom.com)

Scanning Electron Micrograph of the Samples

The micrographs of the samples, as taken by scanning electron microscope, are presented in plates below;
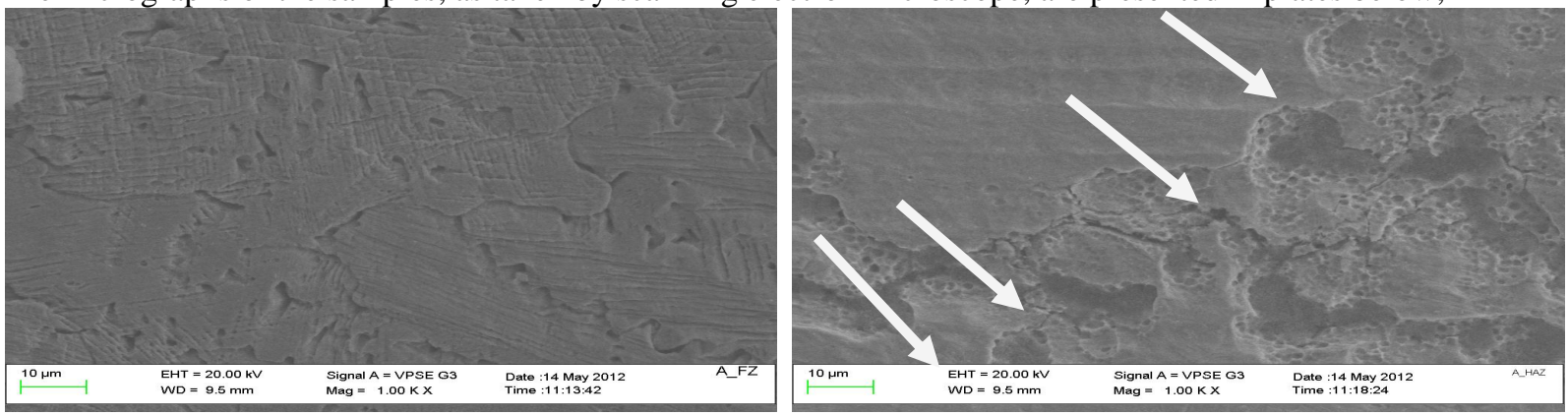

Plate 1:-(a) Micrograph of the Fusion Zone for Sample A.
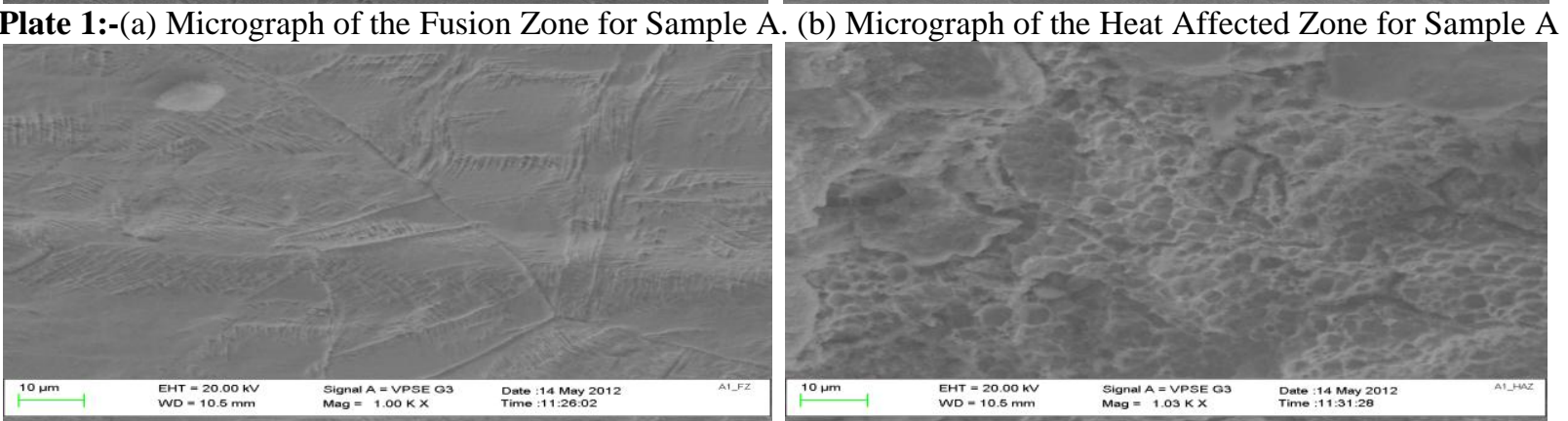

Plate 2:-(a) Micrograph of the Fusion Zone for Sample A1. (b) Micrograph of the Heat Affected Zone for Sample A1 

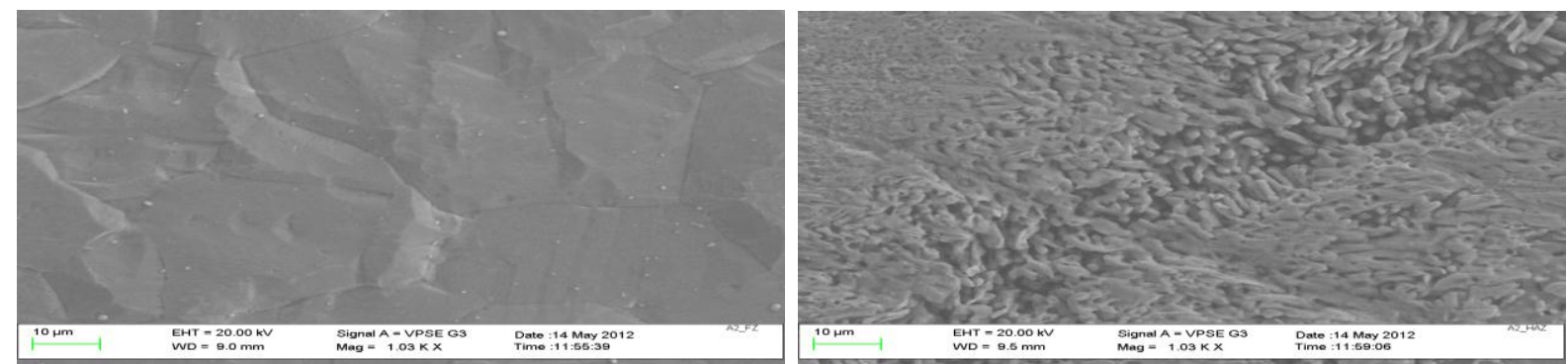

Plate 3:-(a) Micrograph of the Fusion Zone for Sample A2. (b) Micrograph of the Heat Affected Zone for Sample A2
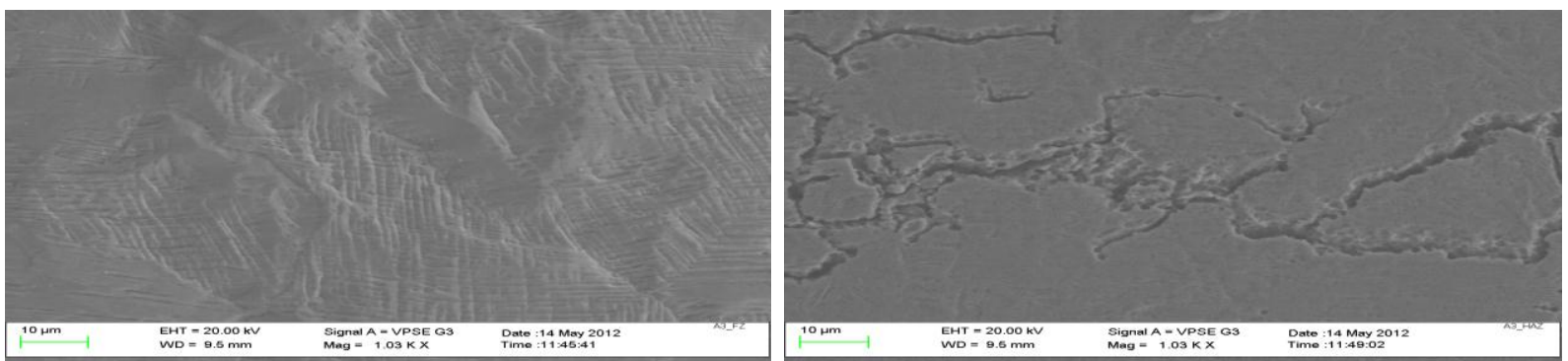

Plate 4:-(a) Micrograph of the Fusion Zone for Sample A3. (b) Micrograph of the Heat Affected Zone for Sample A3

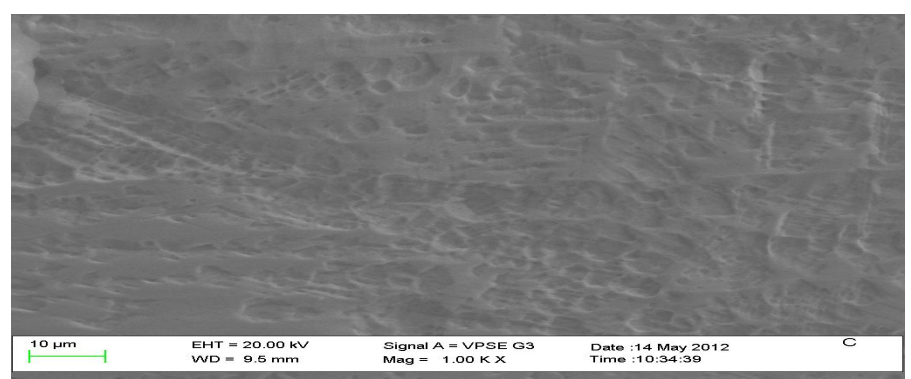

Plate 5:-Micrograph for Sample C

SEM was used to study the morphology of all the welded and as received samples. Plate 5 shows the SEM micrograph of as received sample, Plate 1-4 shows the SEM micrograph of the samples.

Morphological analysis using SEM clearly show difference in the morphology of the heat affected zone and the parts that are not affected, causing the grains of the heat affected zone to be more coarse than that of the unaffected zone (see Plate $1 \mathrm{~b}$ and plate 5 ). The microstructure clearly shows that there will be great influence of this change in morphology to the properties of the welded samples.

The microstructure of the as received sample shows a fine grain boundary and an indication of a better blending of the parent material and the alloying elements (see Plates 5). From the SEM micrograph, there was great variation in morphology of the fusion zone and heat affected zone for same sample. This is due to the difference in the cooling rate of the two zones. (Compare Plate 1a \& b, 2a \& b etc).

Finally, the grains sizes of the heat affected zone for samples A2 is shown to be finer as compared to other samples in the group. This is expected to give them better properties in their group. The basic information obtained from the SEM micrograph is in agreement with observations raised by other researchers [Ibrahim et al 2016; Claes-Oven andSven-Aven,1995; Rohatgi et al 1988], while the relationship between the microstructure and the properties of the developed composite agrees with conclusions of other researchers [ Whitehouse et al, 1991; Zhou and Xu, 1997;Pothan et al 1997; Shangjin et al, 2001;Madugu et al 2010] 


\section{Mechanical Properties of the Samples}

Tensile Properties of the samples

The results of the tensile tests carried out on the samples are shown in figure $2-3$.

The comparison of the tensile strength for the samples with the as received $\mathrm{C}$ one is shown in Fig. 2 below.

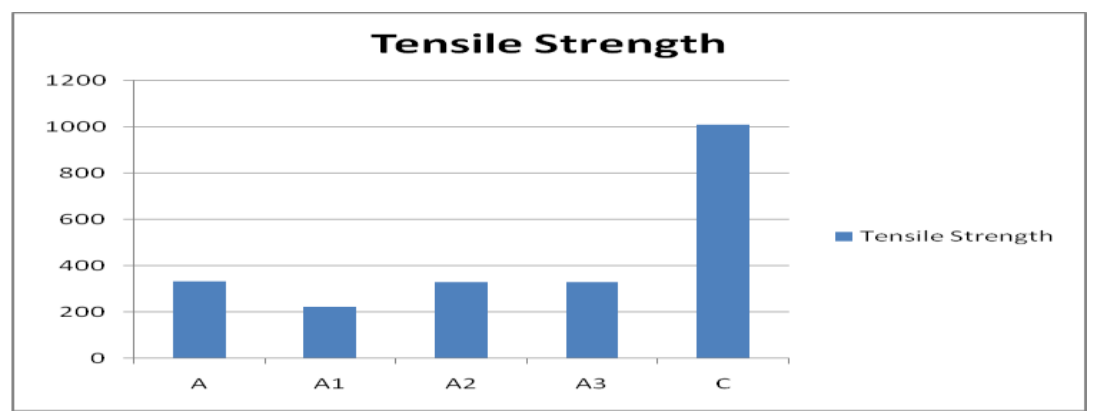

Fig 2:-Tensile Strength for the samples as compared to Control C

The comparison of the percentage elongation (Strain) for the samples with the as received one is shown in Fig. 3 below.

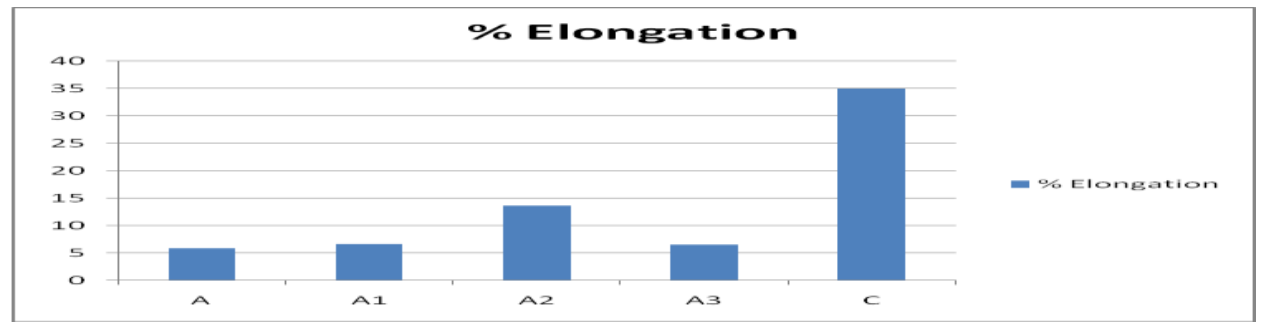

Fig.3:-Percentage Elongation for the samples as compared to Control

The results of the tensile test carried out on the samples, as recorded in the table 3 above shows that, carrying out of post welding treatment increase the ductility of the samples, thereby making the materials to be tougher and decrease their tensile strength. The results also show that, treating the samples in engine oil after welding highly increases their ductility, making them to have highest elongation in their group. This can be associated to the fine grain size as revealed by the micrograph, compared to that of other samples in the group (see Plate $4.3 \mathrm{~b}$ and $4.7 \mathrm{~b}$ )

The results also shows that samples that undergone stress relief treatment after welding has higher tensile strength, next to those treated in lubricating oil, while those treated in neem oil has the lowest in their group. The results obtained from the tensile test of the material are in agreement with those obtained by other researchers [Mohanty et al 2002; Asthana, 1998, Clyne, 2000; Donne et al, 1990; Ibrahim et al 2016]

\section{Impact Properties of the samples}

The results of the impact test carried out on the samples are summarized in figure 4 below.

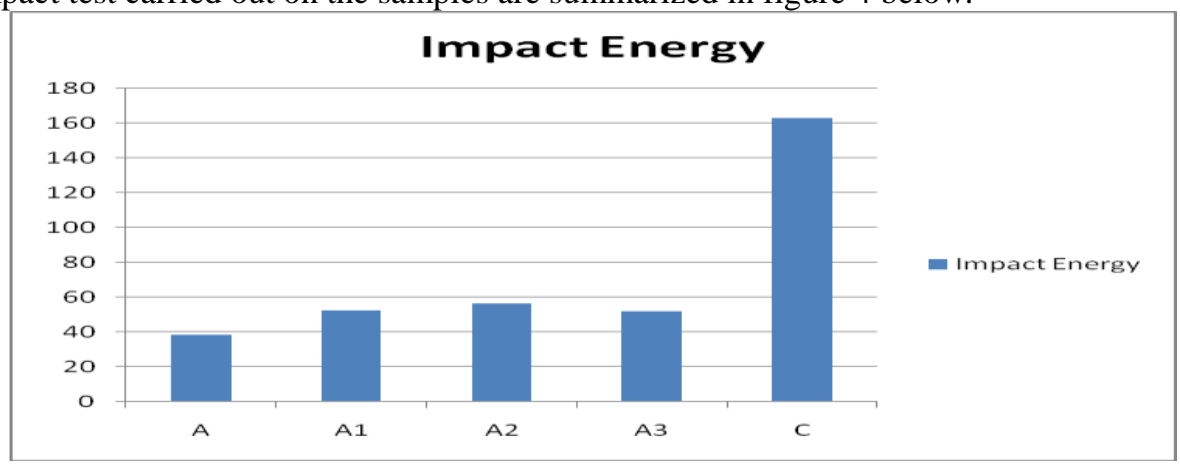

Fig. 4:-Impact Strength for samples as compared to Control 
The results of the impact test carried out on the samples as shows in fig. 4 indicated that the impact energy of the material rises from 38.64J obtained in the non treated sample, to $56.2 \mathrm{~J}$ obtained in sample A2, which is the highest for group A, then fall to $51.86 \mathrm{~J}$ obtained in sample treated in neem oil.

These variations can be related to the morphology of the microstructures, A2 have the finest microstructure in the HAZ in the group. The result obtained from this test is in agreement with those obtained by these researchers, [Donne et al, 1990; Uygur and Dogan,2005; Yetgin et al, 2008; Cottu et al, 1992; Jeffrey, 2000;Mishra et al, 1999; white and Ansell, 1993; Ibrahim et al, 2013; Nowacki and Rybicki, 2007]

\section{Hardness Number for the samples}

The results of the hardness test carried out on the samples are summarized in fig 5 below.

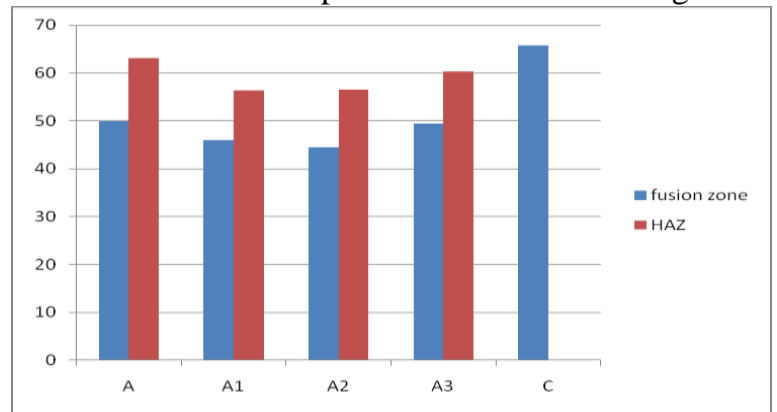

Fig. 5:-Hardness Number for FZ and HAZ as compared to Control

The results obtained from the hardness test show that the hardness numbers of the treated samples differ from those obtained from samples that are not treated, depending on the kind of treatment carried out on them (see Fig. 5). The hardness number of samples that are treated in engine oil is lower as compared to other treated samples in Neem oil. This is expected since the softer a material the higher its ductility thus its toughness. The result also implies that treating the welded samples in engine oil increases their ductility and decreases their hardness.

The variation in the hardness number of the samples also agrees with observations made by other researcher [Donne et al, 1990; Uygur and Dogan,2005; Yetgin et al, 2008; Cottu et al, 1992; Jeffrey, 2000;Mishra et al, 1999; white and Ansell, 1993; Ibrahim et al, 2013; Nowacki and Rybicki, 2007].

\section{Conclusions:-}

From the analyses carried out on the samples and the discussions, following conclusions can be drawn:

1. Both lubricating oil (85W90) and neem oil can serve as quenching medium for post weld treatment of duplex stainless steel.

2. Lubricating oil (85W90) gives better results compared to neem oil in terms of elongation, tensile strength and toughness.

3. Tempering after quenching improved the mechanical properties of the alloy.

4. The tensile test, impact test and the hardness test shows that the two quenching media improved the mechanical properties (toughness and ductility) of this alloy after welding.

\section{References:-}

1. Asthana, R (1998): Solidification processing of reinforced metals. Transport Technology Publications: 67-80.

2. Badji .R, Bouabdullah. M, Kahloun.C, Bettahar. K, Kherrouba. N, (2008): "Effect of solution treatment temperature on the precipitation kinetic of $\sigma$-phase in 2205 duplex stainless steel welds" Material Science and Engineering A., 496(1-2): 447-454.

3. Bhaduri, A.K., Albert, S. K., Ray, S.K. and Rodriguez (2003): Recent Trends in Repair and Refubishing of Steam Turbine Component. Sahdhana. 24(3-4):395-408

4. Claes-Ove. P, Sven-Âven .F (1995). Welding Practice for the Sandvik Duplex Stainless Steels SAF 2304, SAF2205 and SAF2507," AB Sandvik Steel, S-811 81 Sandviken.

5. Clyne, T. W. (2000): Comprehensive Composite Materials. Journal of Metal Matrix Composite, 3:1-8 
6. Cottu, J. P., Coudere, J. J., Viguier, B. and Bernard, L. (1992): Influence of SiC Reinforcement on Precipitation and Hardening of a Metal Matrix Composite., Journal of Material Science., 27(11): 3068-3074. doi:10.1007/BF01154120

7. Dauda, E. T. (2008): Weldability Assessment of Some Locally Sourced Steels., Phd Dissertation Department of Metallurgical Engineering A. B. U Zaria.

8. Donne, S, Krishnadev, M.R and Bouchard, R (1990): Metal and ceramic matrix mechanical behavior., The minerals metals and materials society: 243-251

9. Duplex stainless steel Retrieved, 19th October, 2011 from www.weldingengineer.com.

10. Gunn, R., (1997): Duplex Stainless Steels-Microstructure, Properties and Applications., Abington Publishing, Cambridge.

11. Jeffrey W. Kock, (2000): Physical and Mechanical Properties of Chicken Feather Materials., Msc thesis presented to the academic faculty Georgia Institute of Technology.

12. Labanowski, J and Krzysztofowicz,K. (2005): The Influence of Welding Thermal Cycles on Corrosion Resistance of Duplex Stainless Steel., www.pg.gda.pl/mech/kim/ams/022005/ams02200503.pdf

13. Madugu, I. A, Abdulwahab, M. and Aigbodion, V.S. (2010): Effect of Iron Filings on the Properties and Microstructure of Cast Fibre-Polyester/Iron Filings Particulate Composite., Journal of Alloys and Compound., 476(1-2): 808-811.

14. Mishra S. C., Nadiya Bihari Nayak and Alok Satapathy (1999): Investigation on Bio-waste Reinforced Epoxy Composites., Metallurgical and Materials Engineering Department, National Institute of Technology, Rourkela, India: 119-123.

15. Mohanty A.K., Misra M., Drzal L.T., (2002): Sustainable Bio-Composites from Renewable Resource, Opportunity and Challenges in the Green Materials World., Journal of Polymer and Environment., 10(1-2): 1926

16. Nowacki .J, and Rybicki,P. (2007): Corrosion Resistance of SAW Duplex Joints Welded with High Heat Input., Journal of Achievements in Materials and Manufacturing Engineering., 23( 2): 7-14.

17. Pothan L. A, Thomas S and Neelakantan, (1997): Short Banana Fiber Reinforced Polyester Composites: Mechanical, Failure and Aging Characteristics., Journal of Reinforced Plastics and Composites., 16(8): 744765.

18. Roger, T. and Tony, M. (1999): Newnes Mechanical Engineer's Pocket Book, CBS Publishers and distributors: New Delhi

19. Rohatgi P.K.,. Yarandi, F.M and Liu, Y. (1988): Proceedings of International Symposium on Advances in Cast Reinforced Metal Composites., In: S. G. Fishman and A. K. Dhingra, Eds., ASM International Publication, Materials Park, 249.

20. Shangjin H., Keyu, S., Jie, B., Zengkun, Z., Liang, L., Zongjie, D., and Baolong, Z. (2001): Studies on the Properties of Epoxy Resins Modified with Chain-Extended Ureas, Journal of Polymer., 42: 9641-9647.

21. Ibrahim, T.,Yawas, D.S. and Aku, S.Y.(2013): Effects of Shield Metal Arc Welding Techniques on the Mechanical Properties of Duplex Stainless Steel., Journal of Advance in Applied Science Research, Pelagia Research Library., 4 (5): 190-201

22. Ibrahim, T.K., Leva, I.U., Ilayasu, I. and Yawas, D.S. (2016): Comparative Analysis of Neem and Lubricating (85W90) Oils as quenchants on the Mechanical Properties of Shield Metal Arc welded Duplex Stainless Steel. International journal of scientific and Engineering Research., 7(4): 1825-1836

23. Uygur,I. and Dogan,I.(2005): The effect of TIG Welding on Microstructure and Mechanical Properties of a Butt Joint Unalloyed Titanium., METALURGIJA 44 (2): 119-123

24. White, N.M., Ansell, M.P. (1993): Straw reinforced polyester composites. Journal of Material Science., 18:1549-56.

25. Whitehouse, A. F, Shahani, R. A. and Clyne, T. W. (1991): Metal Matrix Composites: Processing, Microstructure and Properties," In: R. N. Hansen et al., Eds., 12 Ris $\theta$ International Symposium, Ris $\theta$ National Laboratory, Denmark, : 741-748.

26. Yetgin Sukru, Cavdar, O. Cavdar, A. (2008):The Effects of the Fibre Contents on the Mechanical Properties of the Adobes., Journal of Construction and Building Materials., 22(3): 222-227. doi:10.1016/j.conbuildmat.2006.08.022

27. Zhou, W. and Xu, Z.M. (1997): Casting of SiC Reinforced Metal Matrix., Journal of Materials Processing Technology., 63(1-3):358-363.doi:10.1016/S0924-0136(96)02647-7 